\title{
Impact of inhaled corticosteroid use on outcome in COPD patients admitted with
} pneumonia

\author{
A. Singanayagam, J.D. Chalmers, A.R. Akram and A.T. Hill
}

ABSTRACT: The aim of this study was to investigate whether inhaled corticosteroid (ICS) use affects outcome in patients with chronic obstructive pulmonary disease (COPD) admitted with community-acquired pneumonia (CAP).

This was a prospective, observational study of patients with spirometry-confirmed COPD presenting with a primary diagnosis of CAP in Lothian, UK. Outcome measures were compared between ICS users and non-ICS users.

Of 490 patients included in the study, $76.7 \%$ were classified as ICS users. ICS users had higher Global Initiative for Chronic Obstructive Lung Disease (GOLD) stage compared with non-ICS users (mean \pm SD $3.2 \pm 0.8$ versus $2.6 \pm 0.9 ; p<0.0001$ ). There were no significant differences in pneumonia severity (mean \pm SD Pneumonia Severity Index (PSI) $4.2 \pm 0.8$ versus $4.3 \pm 0.8$ ( $p=0.3$ ); mean \pm SD CURB-65 score $2.1 \pm 1.3$ versus $2.3 \pm 1.3(\mathrm{p}=0.07)$ ) or markers of systemic inflammation (median C-reactive protein 148 (interquartile range $58-268$ ) $\mathrm{mg} \cdot \mathrm{L}^{-1}$ versus 183 (IQR 85-302) $\mathrm{mg} \cdot \mathrm{L}^{-1} ; \mathrm{p}=0.08$ ) between ICS users and non-ICS users. On multivariable analysis, after adjustment for COPD severity and PSI, ICS use was not independently associated with 30 -day mortality (OR 1.71, 95\% $\mathrm{Cl} 0.75-3.90 ; p=0.2$ ), 6-month mortality (OR 1.62, 95\% Cl $0.82-3.16 ; p=0.2$ ), requirement for mechanical ventilation and/or inotropic support (OR $0.73,95 \% \mathrm{Cl} 0.33-1.62 ; \mathrm{p}=0.4$ ) or development of complicated pneumonia (OR $0.71,95 \% \mathrm{Cl} 0.25-1.99 ; \mathrm{p}=0.5$ ).

Prior ICS use had no impact on outcome in patients with COPD admitted with CAP.

KEYWORDS: Chronic obstructive pulmonary disease, community-acquired pneumonia, inhaled corticosteroids, outcome

everal large trials have reported increased community-acquired pneumonia (CAP) risk associated with use of inhaled corticosteroids (ICS) in chronic obstructive pulmonary disease (COPD) [1-3]. There is some evidence that patients with COPD who develop pneumonia may experience worse clinical outcomes [4-6], although this association is debated [7-9]. Despite the increased pneumonia frequency observed with use of ICS in COPD, there has been no associated rise in mortality reported by any of the recent trials [1-3]. This has led to speculation that ICS use may increase CAP risk but protect against severe pneumonia or pneumonia-related complications [10, 11].

The aim of our study was to assess the impact of ICS pre-treatment on admission markers of severity and outcome in COPD patients presenting with CAP.

\section{METHODS}

The Edinburgh Pneumonia Study was a prospective observational study of adult patients presenting with a diagnosis of CAP between January 2005 and December 2009 to National Health Service Lothian, UK [12]. This manuscript reports a subanalysis of this study investigating the effect of ICS use on severity and outcome in patients with spirometry-confirmed COPD. The study was approved by the Lothian Research Ethics Committee.

All patients included in the study had a diagnosis of COPD confirmed by spirometry according to the Global Initiative for Chronic Obstructive Lung Disease (GOLD) criteria [13] and presented with a new infiltrate on chest radiograph along with three or more of the following symptoms or signs: cough, sputum production, breathlessness,

\section{AFFILIATION}

Dept of Respiratory Medicine, Royal Infirmary of Edinburgh, Edinburgh, UK.

\section{CORRESPONDENCE}

A. Singanayagam

Dept of Respiratory Medicine

Royal Infirmary of Edinburgh

51 Little France Crescent

Old Dalkeith Road

Edinburgh EH16 4SA

UK

E-mail: aransinga@gmail.com

Received:

May 172010

Accepted after revision:

Nov 232010

First published online:

March 232011 
pleuritic chest pain or signs consistent with pneumonia on auscultation.

Exclusion criteria were: hospital-acquired pneumonia (development of symptoms $>48 \mathrm{~h}$ following admission or discharge from an acute care facility $<2$ weeks prior to admission); active thoracic malignancy; a primary diagnosis of asthma; immunosuppression (defined as long-term ( $>28$ days) use of oral prednisolone at any dose or other immunosuppressive drugs (methotrexate, azathioprine, cyclosporin and anti-tumour necrosis factor- $\alpha$ agents)) or patients with solid organ transplantation; pulmonary embolism; and patients in whom active treatment was not considered appropriate (palliative care).

\section{Study protocol}

For all patients admitted with CAP, a pro forma was completed on admission that included baseline observations (pulse, blood pressure, respiratory rate and temperature) and standard blood tests (full blood count, urea and electrolytes, liver function tests and C-reactive protein). All variables were taken within $4 \mathrm{~h}$ of hospital admission. On admission, patients were risk assessed using the CURB-65 score (confusion, urea $>7 \mathrm{mmol} \cdot \mathrm{L}^{-1}$, respiratory frequency $\geqslant 30$ breaths $\cdot \mathrm{min}^{-1}$, low blood pressure (systolic value $<90 \mathrm{mmHg}$ or diastolic value $\leqslant 60 \mathrm{mmHg}$ ) and age $\geqslant 65 \mathrm{yrs}$ ) and the Pneumonia Severity Index (PSI) (online supplementary material) [14, 15]. All patients received standard antibiotic therapy in accordance with British Thoracic Society guidelines [16].

\section{Assessment of COPD and ICS use}

COPD was defined according to the GOLD criteria [13]. All patients included in the study had a confirmed diagnosis of COPD made by spirometry in primary or secondary care within 6 months of admission to hospital with CAP, while clinically stable. The use of ICSs (either in a single inhaler or in a combination ICS/long-acting $\beta$ - $_{2}$-agonist preparation (LABA)) was recorded on admission. Patients were classified as ICS users if they self-reported prescription of any of these medications on repeat prescription from their general practitioner at the time of admission. The prescriptions for all patients were confirmed by contacting the patient's general practitioner within one working day of admission. All patients classified as ICS users had been taking ICS for $\geqslant 1$ month, prior to admission with CAP. Compliance with medication was not recorded.

Patients using ICS were then further subdivided according to type of ICS used: budesonide (alone or in combination with formoterol), fluticasone (alone or in combination with salmeterol), beclomethasone or ciclesonide.

\section{Outcomes}

The outcomes of interest were 30-day and 6-month mortality, need for mechanical ventilation (MV) and/or inotropic support (IS), and development of complicated pneumonia (complicated parapneumonic effusion, empyema or pulmonary abscess). The indications for MV/IS were left to the discretion of the attending physician. We also assessed length of hospital stay and time to clinical stability, defined using the modified criteria of HALM et al. [17] as the first 24-h period in which the following criteria were met: temperature $<37.2^{\circ} \mathrm{C}$; heart rate $<100$ beats $\cdot \mathrm{min}^{-1}$; respiratory rate $<24$ breaths $\cdot \mathrm{min}^{-1}$; systolic blood pressure $>90 \mathrm{mmHg}$; oxygen saturation $>90 \%$ in room air; able to maintain oral intake; and return to baseline mental status) and the length of hospital stay.

\section{Statistical analysis}

All data were analysed using SPSS version 13 for Windows (SPSS Inc., Chicago, IL, USA). Descriptive statistics of demographic and clinical variables are presented as median (interquartile range), unless otherwise stated. The Chi-squared test was used to compare categorical data between groups. The Mann-Whitney U-test was used for comparison of two groups of continuous data. Kaplan-Meier analysis was used for comparison of survival between ICS users and non-ICS users. The statistical significance was evaluated using the log-rank test.

We used multivariable logistic regression to compare the outcomes of interest in patients with ICS pre-treatment compared with non-ICS users. In the baseline model, we included COPD severity (GOLD criteria) and the PSI. We also used multivariable logistic regression to compare 30-day mortality in ICS users with non-ICS users in the subgroups of intensive care unit (ICU)-admitted patients and those in PSI class 5. In both these models, we included COPD severity (GOLD criteria). A two-tailed p-value $<0.05$ was considered statistically significant for all tests.

\section{Power calculation}

With a sample size of 376 (ICS group) and 114 (non-ICS users), this study is powered for an effect size of $9 \%$ using a twosided, two-sample test with a 5\% level of significance and $80 \%$ power.

\section{RESULTS}

The study enrolled a total of 1,883 patients with CAP. Spirometry results were available for 718 patients, of which

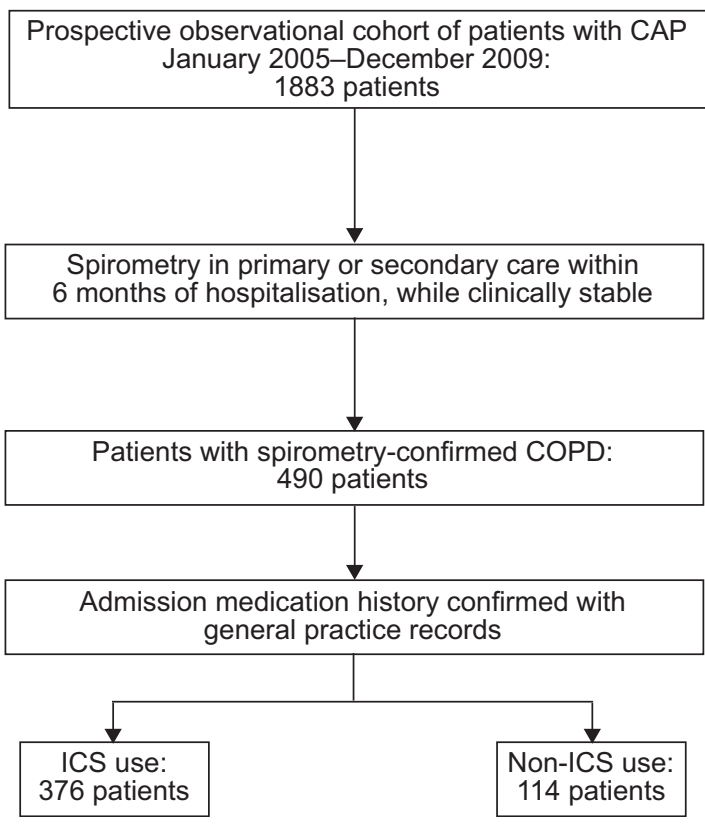

FIGURE 1. Flow chart of patient enrolment into the study. CAP: communityacquired pneumonia; COPD: chronic obstructive pulmonary disease; ICS: inhaled corticosteroid. 


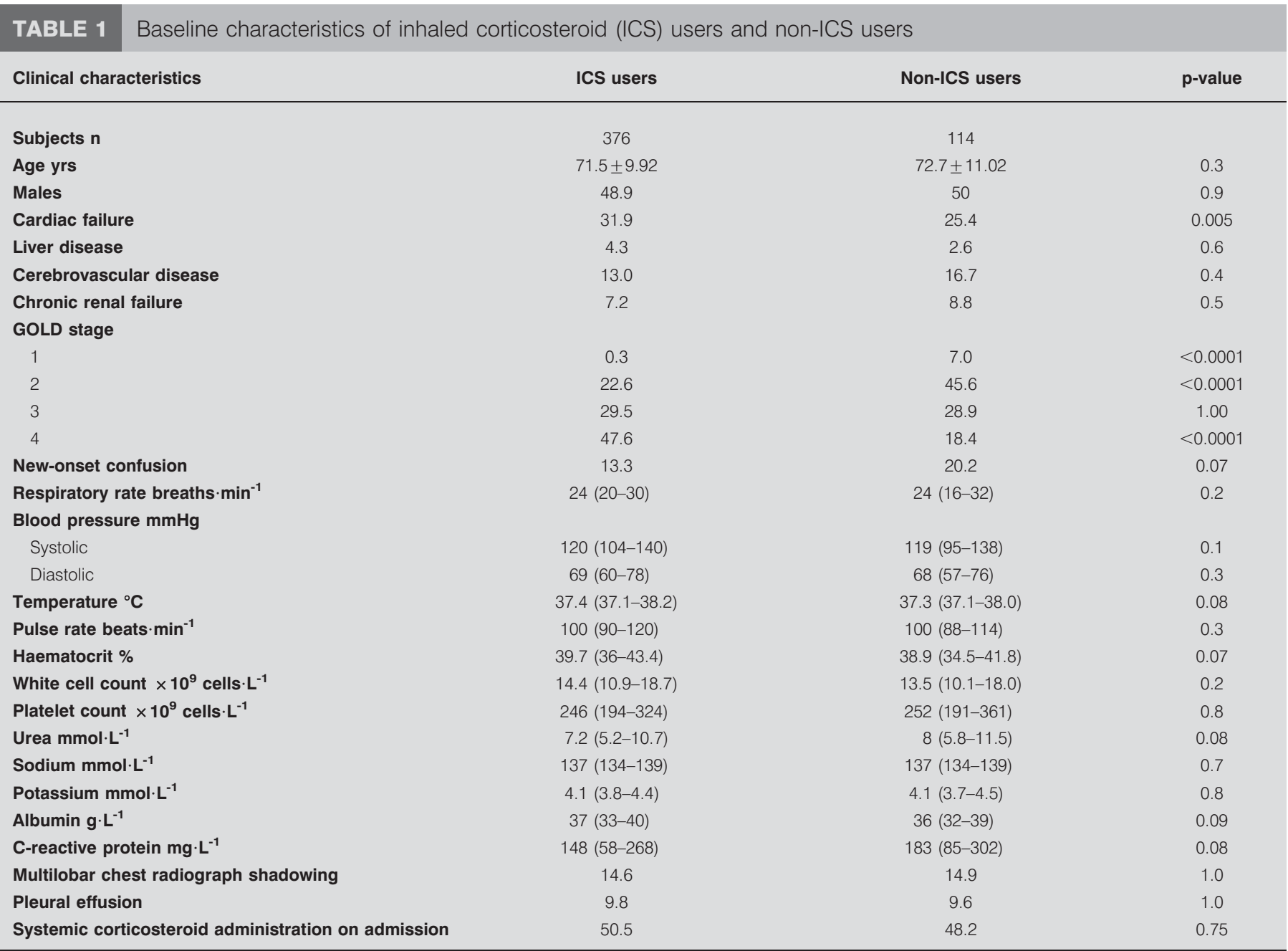

Data presented as mean $\pm \mathrm{SD}, \%$ or median (interquartile range), unless otherwise stated. GOLD: Global Initiative for Chronic Obstructive Lung Disease.

490 confirmed a suspected diagnosis of COPD. 376 patients were classified as ICS users and 114 were not prescribed ICSs. A flow chart of patient enrolment into the study is illustrated in figure 1. There were no patients treated with inhaled therapy in whom spirometry results were not available.

\section{Subclasses of ICS}

Among ICS users, $67.9 \%$ were prescribed a fluticasone/salmeterol combination, $21.1 \%$ were prescribed a budesonide/formoterol combination and $11 \%$ were taking a single ICS inhaler without LABAs. Of the 41 single-agent ICS users, 18 were prescribed fluticasone, 17 were prescribed beclometasone, five were prescribed budesonide and one patient was prescribed ciclesonide. The mean \pm SD doses of ICS prescribed were as follows: fluticasone, $948 \pm 424.8 \mu \mathrm{g} \cdot \mathrm{day}^{-1}$; budesonide, $909.5 \pm$ $374.4 \mu \mathrm{g} \cdot$ day $^{-1}$; and beclomethasone, $741.2 \pm 209.3 \mu \mathrm{g} \cdot$ day $^{-1}$.

\section{Baseline characteristics}

Baseline characteristics of the ICS and non-ICS groups are shown in table 1. ICS users were more likely to have cardiac failure and also be classified with GOLD stage 4 disease, while non-ICS users were more likely to be classified with GOLD stage 1 or 2 disease. Otherwise, there was no significant differences between the two groups in terms of age, comorbidities, clinical parameters, markers of systemic inflammation and radiographic findings. Rates of administration of systemic steroids on admission were similar between the two groups (table 1).

\section{Stratification of ICS and non-ICS users according to CURB- 65 and PSI}

Table 2 shows ICS and non-ICS users stratified according to PSI and CURB-65 classes. There was no significant difference between ICS users and non-ICS users when stratified according to either scoring system.

\section{ICS use and outcome}

Table 3 shows markers of severity and outcome in ICS users and non-ICS users. ICS users had higher mean GOLD stage, indicating more severe COPD. There were no significant differences in 30-day or 6-month mortality, need for MV/IS, development of complicated pneumonia, length of hospital stay, or time to clinical stability when comparing ICS users with non-ICS users. 


\begin{tabular}{|c|c|c|c|}
\hline \multirow[t]{2}{*}{ TABLE 2} & \multicolumn{3}{|c|}{$\begin{array}{l}\text { Inhaled corticosteroid (ICS) users and non-ICS } \\
\text { users stratified according to Pneumonia Severity } \\
\text { Index (PSI) and CURB-65 classes }\end{array}$} \\
\hline & ICS users & Non-ICS users & $\mathrm{p}$-value \\
\hline Subjects $\mathrm{n}$ & 376 & 114 & \\
\hline \multicolumn{4}{|l|}{ PSI } \\
\hline 1 & 0 & 0 & NA \\
\hline 2 & 3.7 & 2.6 & 0.77 \\
\hline 3 & 14.9 & 14.9 & 1.0 \\
\hline 4 & 39.6 & 34.2 & 0.32 \\
\hline 5 & 41.8 & 48.2 & 0.24 \\
\hline \multicolumn{4}{|l|}{ CURB-65 } \\
\hline 0 & 13.3 & 10.5 & 0.52 \\
\hline 1 & 22.9 & 21.1 & 0.80 \\
\hline 2 & 29.8 & 26.3 & 0.56 \\
\hline 3 & 20.5 & 22.8 & 0.60 \\
\hline 4 & 10.9 & 15.8 & 0.19 \\
\hline 5 & 2.6 & 3.5 & 0.75 \\
\hline \multicolumn{4}{|c|}{$\begin{array}{l}\text { Data are presented as } \% \text {, unless otherwise stated. CURB- } 65 \text { : confusion, urea } \\
>7 \mathrm{mmol} \cdot \mathrm{L}^{-1} \text {, respiratory frequency } \geqslant 30 \text { breaths } \mathrm{min}^{-1} \text {, low blood pressure } \\
\text { (systolic value }<90 \mathrm{mmHg} \text { or diastolic value } \leqslant 60 \mathrm{mmHg} \text { ) and age } \geqslant 65 \mathrm{yrs} \text {; } \\
\text { NA: not applicable. }\end{array}$} \\
\hline
\end{tabular}

\section{Survival analysis}

Figure 2 shows Kaplan-Meier analysis for 30-day mortality in ICS users and non-ICS users. There was no significant difference in survival when comparing ICS users with non-ICS users (log-rank test Chi-squared 0.83, one degree of freedom; $\mathrm{p}=0.4)$.

\section{Multivariable analysis}

On multivariable analysis, after adjustment for severity of COPD (GOLD criteria) and PSI score, ICS use was not independently associated with 30-day mortality (OR 1.71, 95\% CI $0.75-3.90 ; p=0.2$ ), 6-month mortality (OR $1.62,95 \%$ CI $0.82-$ 3.16 ; $\mathrm{p}=0.2$ ), requirement for $\mathrm{MV} / \mathrm{IS}$ (OR $0.73,95 \% \mathrm{CI} 0.33-$ $1.62 ; \mathrm{p}=0.4$ ) or development of complicated pneumonia (OR $0.71,95 \%$ CI $0.25-1.99 ; \mathrm{p}=0.5)$.

\section{Outcome in ICU-admitted patients and those with severe pneumonia}

There were 39 patients admitted to the ICU. Mortality in this group was $38.5 \%$. Of those admitted to the ICU, $26(66.7 \%)$ were ICS users and 13 (33.3\%) were non-ICS users. On multivariable analysis, ICS use was not associated with 30-day mortality in the subgroup admitted to the ICU (OR 0.37, 95\% CI 0.07-1.95; $\mathrm{p}=0.3)$.

There were 212 patients in PSI class 5. Mortality in this group was $20.8 \%$. Of those in PSI class 5, $157(74.1 \%)$ were ICS users and $55(25.9 \%)$ were non-ICS users. On multivariable analysis, ICS use was not associated with 30-day mortality for patients in PSI class 5 (OR 1.92, 95\% CI 0.76-4.86; $\mathrm{p}=0.2$ ).

\section{DISCUSSION}

Our study has found that prior ICS use has no impact on severity and outcomes in patients with COPD who are

\begin{tabular}{|c|c|c|c|}
\hline \multirow[t]{2}{*}{ TABLE 3} & \multicolumn{3}{|c|}{$\begin{array}{l}\text { verity and outcome in inhaled } \\
\text { (ICS) users and non-ICS users }\end{array}$} \\
\hline & ICS users & Non-ICS users & p-value \\
\hline GOLD stage & $3.2 \pm 0.8$ & $2.6 \pm 0.9$ & $<0.0001$ \\
\hline CURB-65 class & $2.1 \pm 1.3$ & $2.3 \pm 1.3$ & 0.07 \\
\hline PSI class & $4.2 \pm 0.8$ & $4.3 \pm 0.8$ & 0.3 \\
\hline \multicolumn{4}{|l|}{ Mortality \% } \\
\hline 30-day & 12.0 & 8.9 & 0.5 \\
\hline 6-month & 18.4 & 14.9 & 0.5 \\
\hline Need for MV/IS & 6.9 & 10.7 & 0.2 \\
\hline Complicated pneumonia & 4.0 & 5.4 & 0.8 \\
\hline Time to clinical stability days & $3(2-6)$ & $3(1-5)$ & 0.4 \\
\hline Length of hospital stay days & $6(3-11)$ & $6(4-12)$ & 0.6 \\
\hline \multicolumn{4}{|c|}{$\begin{array}{l}\text { Data presented as mean } \pm \mathrm{SD}, \% \text { or median (interquartile range), unless } \\
\text { otherwise stated. GOLD: Global Initiative for Chronic Obstructive Lung } \\
\text { Disease; CURB-65: confusion, urea }>7 \mathrm{mmol} \cdot \mathrm{L}^{-1} \text {, respiratory frequency } \\
\geqslant 30 \text { breaths } \cdot \mathrm{min}^{-1} \text {, low blood pressure (systolic value }<90 \mathrm{mmHg} \text { or diastolic } \\
\text { value } \leqslant 60 \mathrm{mmHg} \text { ) and age } \geqslant 65 \mathrm{yrs;} \text { PSI: Pneumonia Severity Index; } \\
\text { MV: mechanical ventilation; IS: inotropic support. }\end{array}$} \\
\hline
\end{tabular}

hospitalised with CAP. We assessed a range of clinical outcomes including 30-day and 6-month mortality, need for $\mathrm{MV} / \mathrm{IS}$, development of complicated pneumonia, time to clinical stability, and length of hospital stay. Regardless of which outcome measure was used, we found no significant differences between ICS users and non-ICS users after adjustment for COPD severity (GOLD criteria) and pneumonia severity (PSI criteria).

The hypothesis that ICS use may be associated with improved outcomes of CAP in patients with COPD has been raised by a number of large randomised controlled trials that, despite showing significantly increased pneumonia rates associated with ICS use, have reported no overall increase in mortality [1-3]. A post hoc analysis of the TORCH (Towards a Revolution

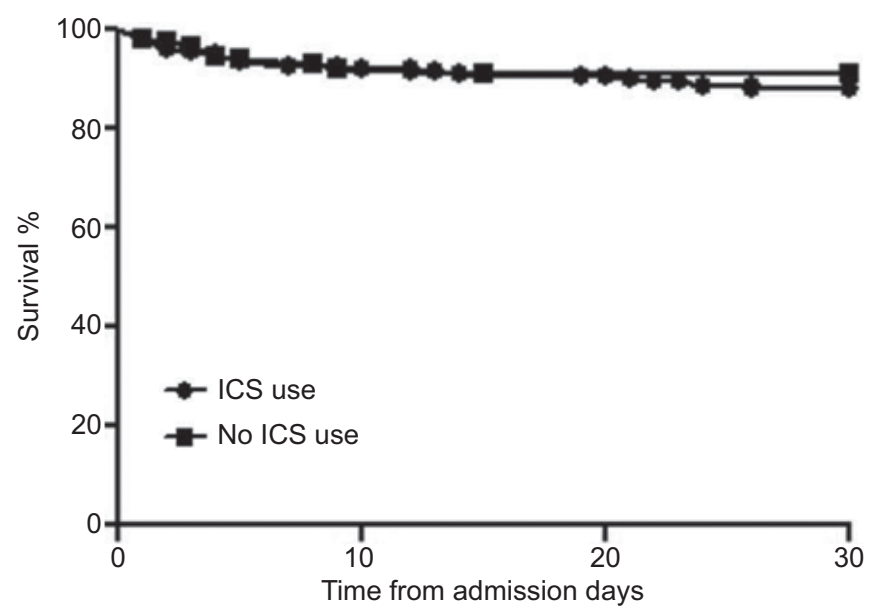

FIGURE 2. Kaplan-Meier 30-day survival analysis in inhaled corticosteroid (ICS) users and non-ICS users. 
in COPD Health) trial has shown that although rates of pneumonia are higher in ICS-receiving groups, there is no difference in serious adverse events (death or hospitalisation) [10]. This has led to the speculation that episodes of pneumonia associated with ICS use may be mild in severity and that ICS may increase the risk of pneumonia but protect against pneumonia-related complications [10,11]. The results of our study do not support this hypothesis. ICSs are proposed to improve outcome in CAP by causing a reduction in airway inflammation and neutrophil influx, leading to a blunted systemic inflammatory response [18-21]. However, we found no significant difference in levels of markers of systemic inflammation, such as C-reactive protein and white cell count, between ICS users and non-ICS users in our study. In addition, there is no convincing evidence that systemic corticosteroid administration improves outcomes in CAP $[22,23]$. This adds further weight to our findings, as locally acting ICSs would, therefore, also be expected to have minimal impact on mortality.

Our findings contradict a recent study by MALO DE MOLINA et al. [21], who analysed a large database of patients aged $>64$ yrs with COPD who were hospitalised with CAP and found that ICS use was associated with reduced 30- and 90-day mortality. Although the current study utilises a smaller cohort, significant methodological differences may explain the discrepancy in findings between the two studies. The study by MALO DE Molina et al. [21] used International Classification of Diseases (ICD)-9 discharge codes to classify CAP, while inclusion criteria for our study required radiographic confirmation of CAP. Previous studies suggest that ICD-9 codes will miss $\sim 25 \%$ of CAP cases admitted to hospital [24]. As there is no specific ICD-9 code for CAP, retrospective studies rely on less precise definitions, such as pneumonia, respiratory failure or sepsis. This raises the possibility that some of the patients included in the study by MALO DE MOLINA et al. [21] may have been misclassified as CAP and, thus, included despite presenting with an acute "nonpneumonic" exacerbation of COPD. ICSs may have differential effects on these two disease entities and if a greater proportion of episodes of CAP were misclassified in one group compared with the other, this may have had a confounding effect on mortality. Furthermore, our study included only patients with spirometry-confirmed COPD, in contrast to MALO DE MOLINA et al. [21], who used ICD-9 code-based definitions of COPD. Patients included in their study could have, therefore, been misclassified with COPD and actually have had an alternative chronic respiratory disease. In addition, we were able to use spirometric data to adjust for severity of COPD. Without adjustment for severity, it is unclear whether the lower rates of mortality seen in ICS users are due to differences in severity of disease between the two groups rather than use of ICS per se. Our data show that ICS use is more common in patients with more severe COPD.

Although the study by MALO DE MOLINA et al. [21] utilised a much larger sample size, power calculations suggest that, based on a sample size of 490 patients, our study is adequate to detect an improvement in survival of $>9 \%$. Notably, the study by MALO DE Molina et al. [21] demonstrated a $24 \%$ reduction in 30-day mortality associated with ICS use. Our study is, therefore, adequately sized to detect such a large effect but may not detect more subtle changes. Further validation of our findings in larger independent cohorts is needed.

The issue of whether ICS use contributes to increased risk of development of CAP in patients with COPD is controversial [11, 25-28] and requires further characterisation. Our study was not designed to address this question but, rather, to determine whether ICS-associated CAP differs from non-ICSassociated CAP in terms of severity and outcome. It has been recently suggested that lower strength ICSs, such as budesonide, may have less influence on development of CAP than higher potency preparations, such as fluticasone [29]. However, due to a lack of detailed information about doses of ICS, duration and compliance with therapy, we were unable to assess whether lower and higher strength ICS had differential effects on outcome in CAP in our study. Variation in dose and formulation presents difficulties when analysing data on treatments from observational studies and this is a recognised limitation to our study.

In summary, this study found no evidence to support the hypothesis that ICS-related CAP has a distinct clinical phenotype, or that prior ICS use improves clinical outcomes in CAP. Our results are in contrast to some of the existing studies and, thus, further independent validation is now required.

\section{SUPPORT STATEMENT}

J.D. Chalmers is supported by a Clinical Research Training Fellowship from the Medical Research Council (London, UK).

\section{STATEMENT OF INTEREST}

None declared.

\section{REFERENCES}

1 Calverley PM, Anderson JA, Celli B, et al. Salmeterol and fluticasone propionate and survival in chronic obstructive pulmonary disease. N Engl J Med 2007; 356: 775-789.

2 Kardos P, Wencker M, Glaab, et al. Impact of salmeterol/fluticasone propionate versus salmeterol on exacerbations $\mathrm{n}$ severe chronic obstructive pulmonary disease. Am J Respir Crit Care Med 2007; 175: 144-149.

3 Wedzicha JA, Calverley PM, Seenmungal TA, et al. The prevention of chronic obstructive pulmonary disease exacerbations by salmeterol/fluticasone propionate or tiotropium bromide. Am J Respir Crit Care Med 2008; 177: 19-26.

4 Rello J, Rodriguez A, Torres A, et al. Implications of COPD in patients admitted to the intensive care unit by communityacquired pneumonia. Eur Respir J 2006; 27: 1210-1216.

5 Restrepo MI, Mortensen EM, Pugh JA, et al. COPD is associated with increased mortality in patients with community-acquired pneumonia. Eur Respir J 2006; 28: 346-351.

6 Holguin F, Folch E, Redd SC, et al. Comorbidity and mortality in COPD-related hospitalisations in the United States. 1979-2001. Chest 2005; 128: 2005-2011.

7 Torres A, Menendez R. Mortality in COPD patients with community-acquired pneumonia: who is the third partner? Eur Respir J 2006; 28: 262-263.

8 Torres A, Dorca J, Zalacaín R, et al. Community-acquired pneumonia in chronic obstructive pulmonary disease. Am J Respir Crit Care Med 1996; 154: 1456-1461.

9 Ruiz De Ona JM, Gomez Fernandez M, Celdran J, et al. Pneumonia in the patient with chronic obstructive pulmonary disease. Levels 
of severity and risk classification. Arch Bronchoneumol 2003; 39: 101-105.

10 Crim C, Calverley PMA, Anderson JA, et al. Pneumonia risk in COPD patient receiving inhaled corticosteroids alone or in combination: TORCH study result. Eur Respir J 2009; 34: 641-647.

11 Singanayagam A, Chalmers JD, Hill AT. Inhaled corticosteroids and risk of pneumonia: evidence for and against the proposed association. QJM 2010; 103: 379-385.

12 Singanayagam A, Chalmers JD, Hill AT. Admission hypoglycaemia is associated with adverse outcome in community-acquired pneumonia. Eur Respir J 2009; 34: 932-939.

13 Global Initiative for Chronic Obstructive Lung Disease. Global Strategy for Diagnosis, Management, and Prevention of COPD www.goldcopd.com/Guidelineitem.asp? $11=2 \& 12=1 \&$ intId $=989$ Date last accessed: March 23, 2010. Date last updated: December 2010.

14 Lim WS, van der Eerden MM, Laing R, et al. Defining community acquired pneumonia severity on presentation to hospital: an international derivation and validation study. Thorax 2003; 58: 377-382.

15 Fine MJ, Auble TE, Yealy DM, et al. A prediction rule to identify low risk patients with community-acquired pneumonia. $N$ Engl J Med 1997; 336: 243-250.

16 Lim WS, Baudouin SV, George RC, et al. BTS guidelines for the management of community acquired pneumonia in adults: update 2009. Thorax 2009; 64: Suppl. 3, iii1-iii55.

17 Halm EA, Fine MJ, Kapoor WN, et al. Instability on hospital discharge and the risk of adverse outcomes in patients with community acquired pneumonia. Arch Intern Med 2002; 162: 1278-1284.

18 Sin DD, Lacy P, York E, et al. Effects of fluticasone on systemic markers of inflammation in chronic obstructive pulmonary disease. Am J Respir Crit Care Med 2004; 170: 760-765.

19 Llewellyn-Jones CG, Harris TA, Stockley RA. Effect of fluticasone propionate on sputum of patients with chronic bronchitis and emphysema. Am J Respir Crit Care Med 1996; 153: 616-621.
20 van Overveld FJ, Demkow UA, Górecka D, et al. Inhibitory capacity of different steroids on neutrophil migration across a bilayer of endothelial and bronchial epithelial cells. Eur J Pharmacol 2003; 477: 261-267.

21 Malo de Molina R, Mortensen EM, Restrepo MI, et al. Inhaled corticosteroid use is associated with lower mortality for subjects with chronic obstructive pulmonary disease and hospitalized with pneumonia. Eur Respir J 2010; 36: 751-757.

22 Salluh JI, Povoa P, Soares M, et al. The role of corticosteroids in severe community-acquired pneumonia: a systematic review. Crit Care 2008; 12: R76

23 Gorman SK, Slavik RS, Marin J. Corticosteroid treatment of severe community-acquired pneumonia. Ann Pharmacother 2007; 41: 1233-1237.

24 Van De Garde EM, Oosterheert JJ, Bonten M, et al. International classification of diseases codes show modest sensitivity for detecting community-acquired pneumonia. J Clin Epidemiol 2007; 60: 834-838.

25 Drummond MB, Dasenbrook EC, Pitz MW, et al. Inhaled corticosteroids in patients with stable chronic-obstructive pulmonary disease. A systematic review and meta-analysis. JAMA 2008; 300: 2407-2416.

26 Singh S, Amin AV, Loke YK. Long-term use of inhaled corticosteroids and the risk of pneumonia in chronic-obstructive pulmonary disease. A meta-anaysis. Arch Intern Med 2009; 169: 219-229.

27 Woodhead M. Inhaled corticosteroids cause pneumonia... or do they? Am J Respir Crit Care Med 2007; 176: 111-112.

28 Rees PJ. Inhaled corticosteroids do not reduce mortality but increase pneumonia in COPD. Evid Based Med 2009; 14: 74.

29 Sin DD, Tashkin D, Zhang $X$, et al. Budesonide and risk of pneumonia: a meta-analysis of individual patient data. Lancet 2009; 374: 712-719. 